Appendix 1. Sociodemographic Characteristics Questionnaire

\title{
Sociodemographic Characteristics
}

What is your date of birth? (MM/DD/YYYY)

Which of the following best describes your sex at birth?

\section{Female (1)}

Male (0)

Which of the following best describes your sex now?

\section{Female (1)}

Male (0)

Which of the following best represents how you think of yourself?

Lesbian or gay (1)

Straight, that is, not lesbian or gay (2)

Bisexual (3)

Something else (4)

I don't know (5) 
What is your marital status?

Married (1)

Living as married (2)

Divorced (3)

Widowed (4)

Separated (5)

Single, never been married (6)

Are you Hispanic or Latina/o?

Yes (1)

No (0)

What is your race?

Mark all that apply.

Black or African American (1)

White (2)

Other (please specify how you would describe your race below): (3) 
What is the highest grade or level of schooling you completed?

I did not have a high school diploma or GED (please specify highest grade completed below): (1)

\section{High school diploma (2)}

\section{GED (3)}

Post-high school training other than college (e.g., vocational or technical school) (4)

Less than one year of college (5)

More than one year of college (6)

College graduate (undergraduate degree) (7)

Other (please specify the highest level of schooling you completed below): (8) 